\title{
A Case of Primary tuberculosis of the tongue mimicking malignancy
}

\author{
Muhammad Nazrul Islam¹, Md Mesbah Uddin Khan², Mohammad Asaduzzaman
}

Biswas $^{3}$, Mohammad Shohel Showkath ${ }^{4}$,

\begin{abstract}
:
Tuberculosis of the tongue is a very rare event even in a areas and countries in which tuberculosis is endemic. The disease can present itself in a variety of clinical appearances, most of which may mimic malignant lingual neoplasm's clinically. Here we report a case of lingual non healing ulcer in a 44 years female which was clinically suspected as malignant ulcer. The diagnosis of lingual tuberculosis was made by histopathology.
\end{abstract}

Key words: Lingual tuberculosis, non-healing ulcer, extra-pulmonary TB, tongue ulcer.

Introduction:

Tuberculosis is a chronic granulomatous disease caused mainly by Mycobacterium tuberculosis, Mycobacterium bovis and other atypical mycobacterial species ${ }^{1}$. The global burden of the disease was 13.7 million cases in $2007^{2}$. Fifty five percent of the new cases reported in 2007 were from Asia. Despite the

1. Assistant Professor, Department of ENT \& HNS, Diabetic Association Medical College, Faridpur.

2. Associate Professor, Department of Dermatology and Venerology, Diabetic Association Medical College, Faridpur.

3. Assistant Professor, Department of Respiratory Medicine, Diabetic Association Medical College, Faridpur.

4. Assistant Professor, Department of Microbiology, Diabetic Association Medical College, Faridpur.

5. Register, National Institute of ENT, Tejgaon, Dhaka.

Address of correspondence: Dr. Muhammad Nazrul Islam, Assistant Professor, Department of ENT \& HNS, Diabetic Association Medical College, Faridpur, Mobile: +88 01718544543 ,

E-mail: dr.nazrul.cmc40@gmail.com very high incidence, globally and nationally , tuberculosis of the tongue is the rare ${ }^{3}$. Tuberculosis chiefly affects the pulmonary system but it can also involve extrapulmonary sites including the head and neck region. Primary tuberculosis of the oral cavity is exceedingly rare with the tongue being the most commonly affected site. Tuberculosis of the tongue usually presents as a chronic non-healing mucosal ulceration but may occur as nodules, fissures, plaques or verrucous proliferations ${ }^{4,5}$.

\section{Case report:}

A 44 years old female residing in Kanaipur, Faridpur presented to us in the Department of ENT \& HNS of Diabetic Association Medical College Hospital Faridpur, with the complaints of ulcerated lump in the tongue, for last four months, with discomfort and increased salivation for last 20 days. There was no history of cough, fever and hemoptysis or weight loss. The patient belonged to low socioeconomic strata and was an occasional tobacco chewer since last 15 years. 
On examination, her general built and height were normal. Oral cavity examination showed $2 X 3 \mathrm{~cm}$ irregular and hard lump with ulcer in the centre on the dorsum of the anterior two third of tongue (left side) near the midline.

The swelling was non-tender and just cross the midline. Nasopharynx and oropharynx were also clinically normal. Left submandibular lymph node was found to be enlarged, non-tender and mobile measuring $2 \times 1 \mathrm{~cm}$. A provisional diagnosis of malignancy was considered.

Routine blood investigations (CBC, FBS, RFT, ESR) were within normal limits. Serological tests for HBV, HCV, HIV and syphilis were negative.

Biopsy taken from ulcer margin showed granulation tissue, acute on chronic

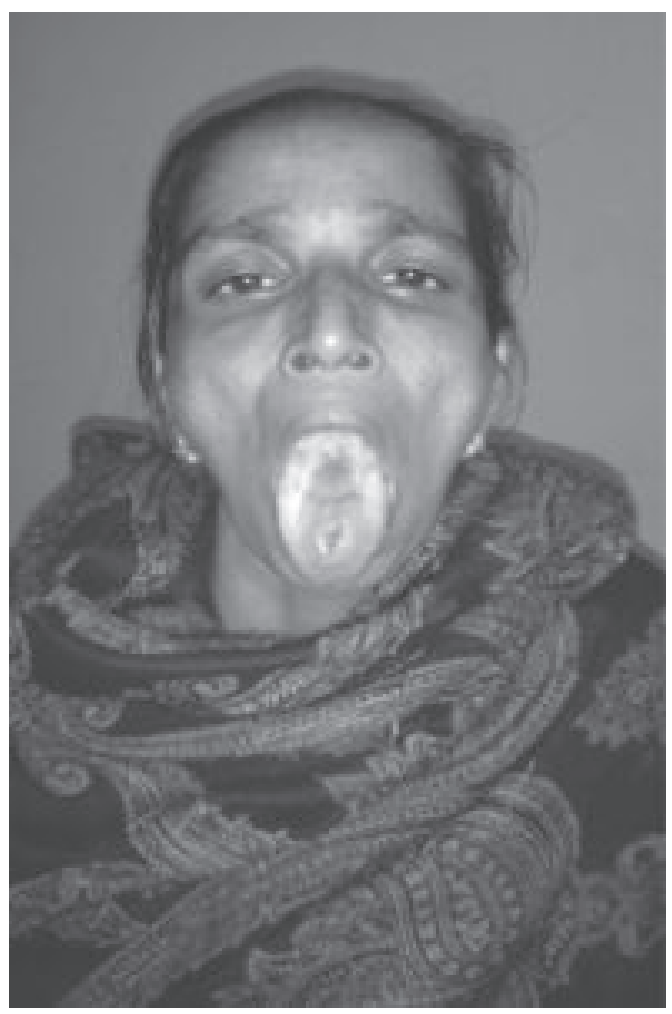

Fig.-1: Photograph of the patient before treatment.

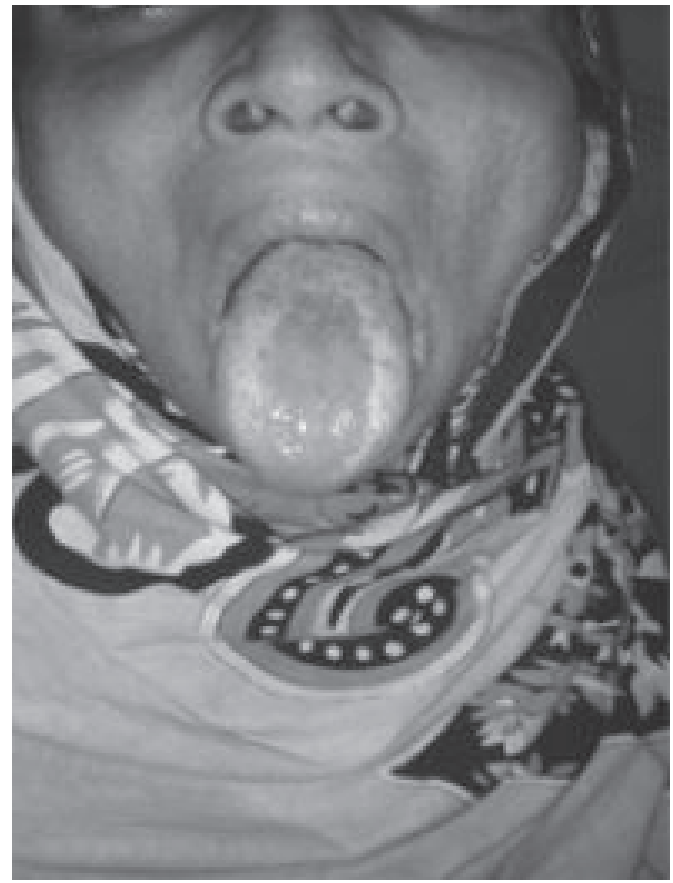

Fig.-2: Photograph of the patient after six months anti TB treatment.

inflammation, epitheloid cells, granuloma with langhans giant cells. FNAC of the left sub mandibular lymphnode revealed tuberculous lymphadenitis. Further investigations include PPD, sputum for AFB and CXR, all of which were negative for the diagnosis of pulmonary tuberculosis thus confirming the diagnosis of primary tuberculosis of the tongue in our case. Our patient was started on DOTs category II and the size of lump shrank in 20 weeks. The lesion completely regressed after 6 months on ATT.

\section{Discussion:}

The World Health Organization (WHO) estimates that 2 billion people or one third of the world's population are infected with tuberculous bacilli and the global tuberculosis incidence is growing at $1 \%$ a year ${ }^{6}$. Despite the staggering figures, tuberculosis of the tongue is a rarely described entity with a rate of $0.1 \%{ }^{7}$. Tongue is the most commonly 
affected structure of oral cavity ${ }^{8}$. It may occur as primary or secondary to tuberculosis of other organs ${ }^{9}$. Secondary lesions are suspected to be caused by implantation of infected sputum into a break in the mucosal surface during coughing episodes. In primary tuberculosis organisms are directly inoculated in mucous membrane. A breach in mucosa due to any reason is one of important predisposing factor ${ }^{10}$. Transmission during dental practice has also been described ${ }^{11}$.

In a large series by Komet et al (1965) the most common presenting symptoms of lingual tuberculosis were pain on deglutition, followed by burning sensation and otalgia ${ }^{12}$. The most common site of lingual tuberculosis described in the literature are lateral border followed by tip, posterior third, middle third, ventral surface and anterior surface ${ }^{13}$.

The differential diagnosis of tongue tuberculous lesions include malignancy, granulomatous disease, syphilis, traumatic and apthous ulcers, mycotic infections ${ }^{14}$. Many forms of presentations may mimic malignancy as nodular and ulcers not typical tuberculosis. Tubercular ulcers are usually more irregular than punched out lesions of carcinoma ${ }^{15}$. The ulcer is usually formed by breakdown of tubercles and usually has undermined edege ${ }^{13}$. In our case irregular and hard lump with ulcer in the centre on the dorsum of the anterior two third of tongue(left side) near the midline.

Diagnosis is made by identification of a caseating granuloma on biopsy. Deeper biopsies are always advocated for ulcers of tongue since superficial biopsies may not reveal the aetiology due to epithelial hyperplasia ${ }^{16}$.

Patients with tongue tuberculosis respond well to antituberculous therapy because tongue is highly vascular ${ }^{17}$. In most cases tongue lesions heal completely within few months. Regarding duration of treatment in patients with extrapulmonary TB involving the oral cavity, the mean time from available reports ranged from 6 to 15 months ${ }^{18}$.

\section{Conclusions:}

Worldwide, lingual tuberculosis is rare, clinician must take tuberculosis into greater consideration and possible diagnosis when diagnosing chronic and/or recurrent lingual lesions even in the absence of pulmonary TB. The importance of early diagnosis and treatment lies in the fact that it can be easily confused with neoplastic or traumatic etiologies.

\section{References:}

1. Prabhu SR, Daftry DK, Jonson NW. Oral diseases in tropics. Oxford University Press; 1993.

2. World Health Organization. Global tuberculosis control: epidemiology, strategy, financing [Internet]. Geneva: World Health Organization; 2009. Available from: http//whqlibdoc.who.int/ publications/2009/9789241563802eng.pdf

3. Wang WC, Chen YK, Lin LM. Tuberculosis of the head and neck: a review of 20 cases. Oral Surg Oral Med Oral Pathol Oral Radiol Endod 2009; 107:381-6. Epub 2009 Jan 20.

4. Gupta PP, Fotedar S, Agarwal D, Sanswal P. Primary tubercular glossitis in an immunocomprtent patient. Hong Kong Med J 2009; 13(4): 330-331.

5. Sareen D, Sethi A, Agarwal AK. Primary tuberculosis of the tongue: a rare nodular presentation. Br Dent J 2006; 200(6):321-322.

6. WHO website: www.who.int/entity/tb/ publications/global-report/en/index.html. Tuberculosis-the global burden. Trends 
in TB incidence in 9 regions of the world (2005).

7. Iype EM, Ramdas K, Pandey M, Jayasree K, Thomas G, Sebastian P, et al. Primary tuberculosis of the tongue: report of three cases. $\mathrm{Br} \mathrm{J}$ Oral Maxillofac Surg 2001 Oct; 39(5): 402403.

8. Koksal D, Acican T, Kanat F. Tuberculous ulcer of the tongue secondary to pulmonary tuberculosis. Aust N Z J Med 2000;30: 518-519.

9. Ramesh V. Tuberculoma of the tongue presenting as macroglossia. Cutis 1997;60: 201-202.

10. Ghose SM. Ulcers of tongue. J Indian Med Assoc 1966;41:377.

11. Leslie D, Nancy WB. General and Oral Pathology for the Dental Hygienist. Koger B, Dietz K, Bradshaw N, Aiello G, eds. Lippincotte Williams and Wilkins, Philadelphia, PA, 2008; 243245.
12. Komet et al. Tuberculosis of oral cavity. A.M.A. Arch. Otolaryngol. 1965;82:649.

13. Soni N.K, Chatterjee P and Nahata S.K. Tuberculosis of the tongue. Ind. J. Tub. 1980;28:22.

14. Arinc S, Arinc B, Bayal I, et al. Secondary lingual tuberculosis: a case report. Turkish Respir J 2003;4:25-26.

15. Bhadarkar, Kasbekar P, Shah V G et al. Atypical presentation; diffuse glossitis, fissures or tuberculoma reported. Tropical Doctor. 1993; 23:4142.

16. A.P. Bhat, H.M. Dholakia : Tuberculosis of oral mucosa. Journal of Indian Dental Association. 1974;46:161.

17. Von Arx DP. Oral tuberculosis. Br Dent J 2001; 190(8):420-422.

18. Kakisi O.K., Kechagia A.S., Kakisis I.K., Rafailidis P.I., Falagas M.E. (2010). Tuberculosis of the oral cavity: a systemic rivew. Eur. J. Oral. Sci. 118,103-109. 